WS07-A03

\title{
Induced Seismicity in Underground Gas Storage - The Case of Castor, Offshore NE Spain
}

\author{
R. del Potro* (Geostock Iberia) \& M. Diez (University of Bristol)
}

\section{SUMMARY}

Oil and Gas operations have the potential to induce earthquakes, and this is becoming an increasing concern for operators and regulators. Here we present the case of the Castor Underground Gas Storage (UGS), offshore NE Spain, where seismicity was induced during the first phases of gas injection. The microseismicity that occurred during the injection period, and which was not felt, evolved into magnitude 4 events almost two weeks after the end of the injection. The largest earthquakes of the sequence were weakly felt by coastal populations (EMS-98 Intensity III) and, in spite of posing no risk, pressed the authorities to halt all activity in the UGS. Here we compile the results from the major studies of the Castor seismicity: earthquake relocations and source mechanisms, and use new tools to characterise the seismicity and its relation to the gas injection. Cases of induced seismicity, such as Castor, where the external forcing is known, can contribute significantly to our understanding of the response of the crust to stress perturbations caused by fluid movement and the associated rupture events. 
1-4 June 2015 I IFEMA Madrid

\section{Introduction}

Castor UGS is an underground gas storage in the Valencia Trough, $22 \mathrm{~km}$ off the coast of northeast Spain, in an area of low natural seismicity (Figure 1). Castor UGS was completed in 2012 and it is the largest UGS in Spain in terms of volume of working gas and extraction rates. The third period of gas injection in September 2013 induced small magnitude earthquakes, which, two weeks after the end of the injection, developed into mainshock $(\mathrm{M} \sim 4)$-aftershock sequences, returning after to nearbackground levels. Castor UGS makes use of the depleted Amposta oil reservoir, where $56 \mathrm{Mbbls}$ of oil $(9106 \mathrm{~m} 3)$ were extracted in the 1980s. The reservoir lies within the secondary porosity of a karstic Lower Cretaceous limestone formation, and is a mixed-type stratigraphic-structural trap: bound by a listric fault to the west and capped by $1700 \mathrm{~m}$ of clays and sands (Figure 1). It has high transmissivity, allows for fast gravitational segregation of fluids and has a very active water-drive: during exploitation of the oil reservoir the volume of water extracted was $<1 \%$ and the pressure drop was transient and $<3$ bar.

(a)

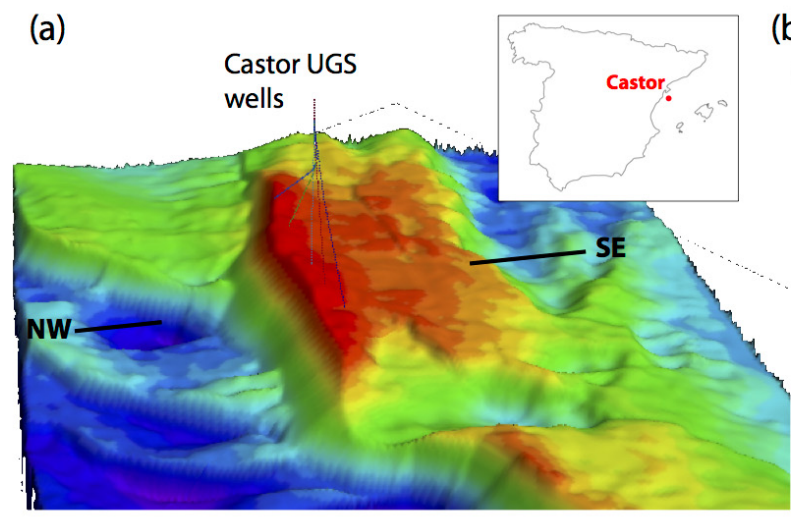

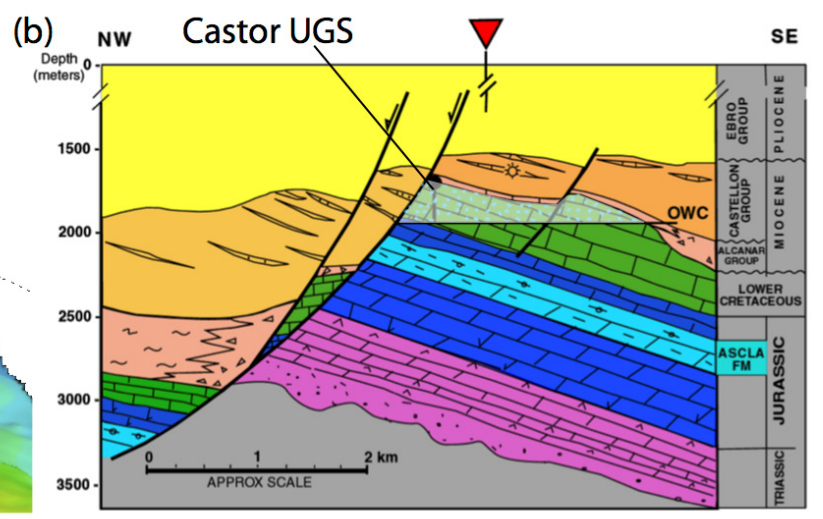

Figure 1 The Castor/Amposta structure: (a) oblique view of the top of the reservoir formation (green unit in (b)), interpreted from the 3D seismic block and (b) cross-sectional sketch of the geological structure (modified from Seemann et al., 1990). The white region in (b) shows the extent of the Castor $U G S, O W C$ indicates the depth of the original oil water contact in the Amposta reservoir. The inset shows the location of Castor.

\section{Geomechanical studies of Castor UGS}

Geomechanical studies of Castor UGS relevant for induced seismicity were carried out during the various development stages and included: (i) The study of the stress tensor from borehole breakouts, anisotropy logging and density columns, (ii) maximum bearing pressures from leak-off and minifrac tests, (iii) potentially active faults were identified from newly acquired 3D reflection seismic data (iv) geomechanical models (analytical and numerical) were developed to study the identified faults, (v) local stations were added to the seismic network, which was surveyed for two years prior to the start of gas injection and continued to be surveyed in real-time during the gas injections, and (vi) pressure and temperature gauges were installed in observation wells. Together, the conclusions of the above mentioned studies indicate that Castor is in an area of low natural seismicity, that from a geomechanical standpoint the structure is suitable for gas storage, and that slip on nearby faults was not expected for the small pressure variations caused by the storage operations.

\section{Gas injection and earthquake sequence}

Two periods of gas injection took place in June and August 2013, as planned. The third phase started on September $2^{\text {nd }} 2013$ and lasted until September $17^{\text {th }}$. The maximum pressure increase in the aquifer was transient and $\sim 2.3$ bar as registered by the pressure sensors in three observation wells. The first earthquake was detected on September $5^{\text {th }}$ (Figure 2). Small magnitude seismicity $(\mathrm{M}<3)$ was recorded during the rest of the injection, though none of the earthquakes were felt. This seismic 


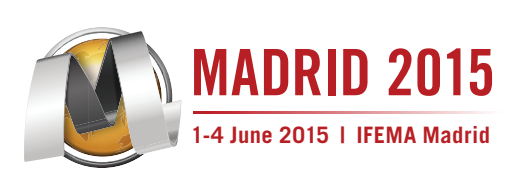

activity appeared to decrease following the end of the injection, however, one week later, on September $24^{\text {th }}$ larger magnitude earthquakes occurred. The seismic activity culminated in a series of M4 earthquakes between October $1^{\text {st }}$ and $4^{\text {th }}$, after which the activity gradually returned to background levels. The largest events were felt in coastal populations with EMS-98 intensity III (Weak).
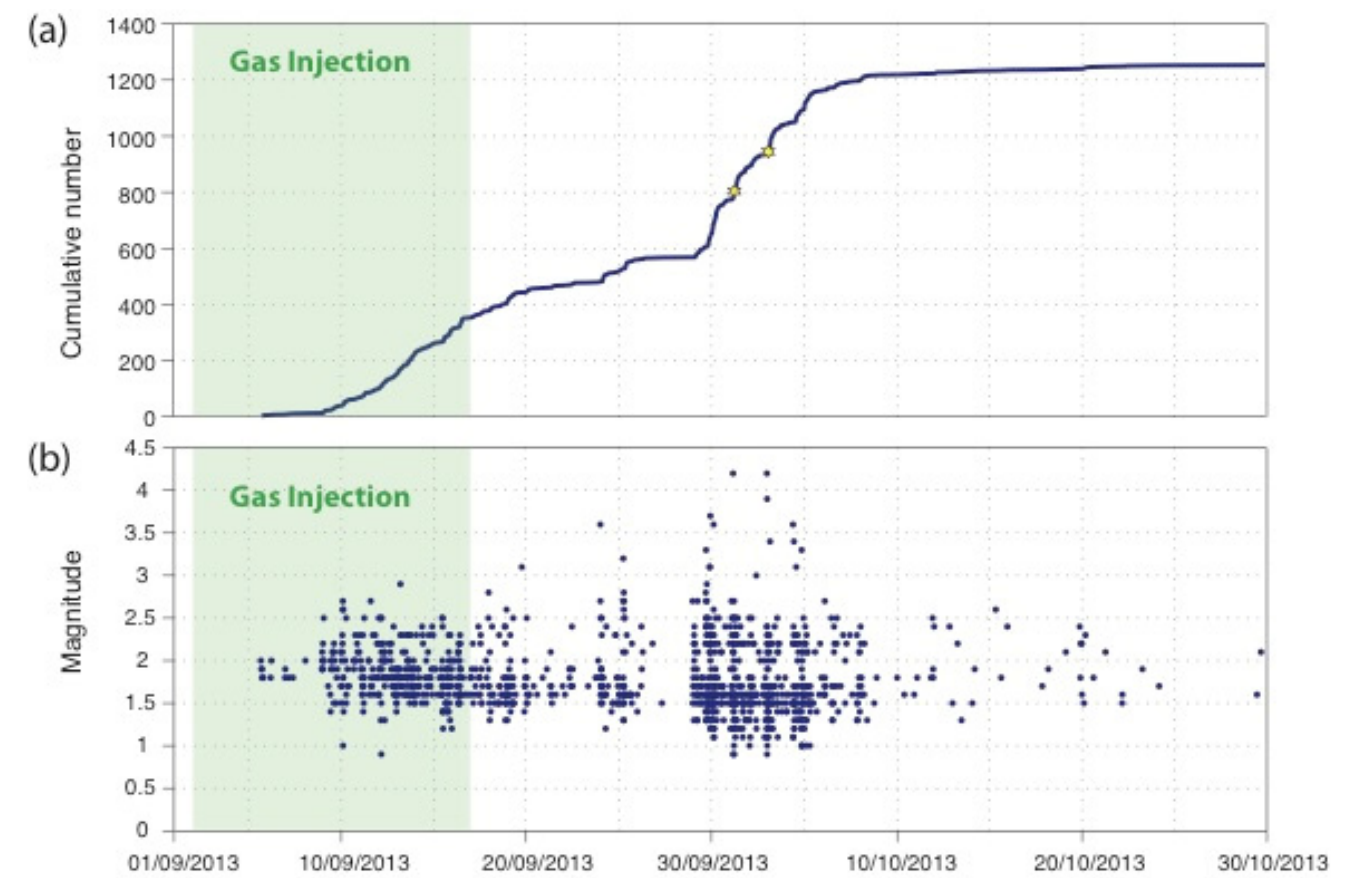

Figure 2 Plots of the seismic sequence (a) total number of earthquakes and (b) earthquake magnitudes versus time. The green region indicates the period of gas injection. The largest magnitude earthquakes (yellow stars in (a)) took place almost two weeks after the injection was stopped.

The combined study of earthquake relocations and focal mechanism by Cesca et al. (2014) indicates that the seimogenic fault is small, it is located within the limestone formation that hosts the reservoir, most likely beneath the gas bubble, it has a SW-NE direction, it dips to the south east and it has leftlateral strike-slip kinematics. Such fault has little or no vertical offset and hence does not have a clear signal in the reflection seismic data. We further study the correlation of the seismicity with the gas injection with tools of statistical seismology. Of particular interest is the application of the weighted average magnitude method, which shows escalations in average magnitude of the seismic events (or energy release of the system), which we interpret as rupture events, and which correlate with changes in injection rate. Furthermore, it shows that the system became unstable at some point during the injection, amplifying small fluctuations of the stress field, that possibly lead to the events of $M \sim 4$ two weeks after the injection stopped.

\section{References}

Cesca, S., Grigoli, F., Heimann, S., González, Á., Buforn, E., Maghsoudi, S., Blanch, E. and Dahm, T., 2014. The 2013 September-October seismic sequence offshore Spain: a case of seismicity triggered by gas injection? Geophysical Journal International, 198(2), 941-953.

Seemann, U., Pumpin, V.F. and Casson, N., 1990. Amposta oil field. Proceedings of the AAPG Treatise of Petroleum Geology: Atlas of Oil and Gas Fields, Structural Traps II: Traps Associated with Tectonic Faulting, American Association of Petroleum Geologists, Tulsa, Oklahoma, USA, pp. 20. 